\title{
Muddying the waters: Sediment water cation exchange reduces silicate weathering feedback
}

E.T TIPPER ${ }^{1}$, E. I. STEVENSON ${ }^{1}$, V.ALCOCK ${ }^{1}$, A.C.G. KNIGHT $^{1}$, C.S. LARKIN ${ }^{1}$, L. FENG ${ }^{1}$, M.J. BICKLE ${ }^{1}$, J.J.BARONAS ${ }^{1}$, K.E.RELPH ${ }^{1}$, R.G. HiLtON ${ }^{2}$, G.HugheS ${ }^{1}$

${ }^{1}$ Department of Earth Sciences, University of Cambridge, Cambridge, CB23EQ, UK ett20@cam.ac.uk

${ }^{2}$ Durham University

Rivers are the planetary arterial network, circulating water, sediment and nutrients from mountainous regions to floodplains and the oceans.

Silicate mineral dissolution reactions remove carbon dioxide from the atmosphere, providing a key negative climate feedback, on million-year time-scales. The dissolved load in rivers provides the prime constraint on silicate dissolution fluxes.

We show that in some river systems, up to $50 \%$ of the dissolved load is carried as a reactive exchange pool in river borne suspended particulate material, bonded weakly to mineral surfaces. We determined the exchange pool chemistry in eight of Earth's largest river systems. Strontium isotopes demonstrate that the exchange pool is in equilibrium with the local river water. Most large river basins contain a proportion of ancient marine sedimentary rocks with an exchange pool that was likely to be part marine in origin and dominated by sodium. This ancient marine sodium contributes to the modern river chemistry by exchanging with calcium (cation exchange). We quantify the maximum possible effect on the silicate weathering flux by comparing the riverine sediment exchange pool and river water chemistry. In some large rivers cation exchange with sedimentary rocks could account for the majority of sodium in the river water, reducing the sodium derived silicate weathering flux. This is most important in regions of high erosion and high sediment loads where chemical weathering reactions have maximum sensitivity to the negative climate feedback. At a global scale, we estimate that silicate weathering fluxes have been over-estimated by a maximum of $30 \%$. 